\title{
AN EXAMINATION OF RELATIONSHIP BETWEEN CAREER MATURITY AND MULTIPLE FACTORS BY FEATURE SELECTION
}

\author{
Shuxing Zhang ${ }^{1}$ and Qinneng $\mathrm{Xu}^{2}$ \\ ${ }^{1}$ Shenzhen College of International Education, Shenzhen, China \\ ${ }^{2}$ Shenzhen Liangyi Information Technology Co., Ltd, Shenzhen, China
}

\begin{abstract}
The purpose of this study is to investigate the relationship between career maturity and a branch of factors among senior school students. The sample data were collected from a total of 189 students. The linear relationship between career maturity and 72 factors were tested by using feature selection methods. LASSO and forward stepwise were compared based on crossvalidation. The results showed that LASSO was a feasible method to select the significant factors, and 12 of the total 72 factors were found to be important in predicting career maturity.
\end{abstract}

\section{KEYWORDS}

Career maturity, Feature selection, LASSO, Stepwise.

\section{INTRODUCTION}

Since the 20th century, career development has been considered as a crucial topic. An individual's career development can be promoted by accelerating maturity, ability, skills, talent, and interests [1]; this viewpoint is supported by previous studies [2, 3]. Emphasis of this kind of promotion in education is necessary in order to enhance career development, and there is research suggesting that career preparation should be carried out early at school [4]. Career guidance at school is important in helping students to develop the knowledge and skills needed for making appropriate choices, managing transition in learning and moving into the workplace [5]. An early career development is also very significant for students, especially for those at high school, in the consideration that they are going to face the significant choice for colleges and major, which will have great effect on their lifetime career direction [6].

The concept of vocational maturity was first introduced by Super in 1955 [7], and then slowly replaced by the phrase "career maturity" [8], defined as the level of progress on career development tasks of an individual [9]. The concept of career maturity emphasizes that career is a continuous and dynamic process, and it can represent the degree of preparation an individual has, to face the tasks in career development [10]. In this case, career maturity can be a standard to measure how well a student has idea about his/her future career direction.

In previous studies, the relationship between career maturity and other influential factors has been widely investigated. Park [11] used correlation analysis and hierarchical regression to investigate the relationships between proactive personality, career indecision, and career maturity. Emerson [12] analyze the association between career maturity and decision-making self-efficacy based on correlation analysis and linear regression. Rahim et al. [13] focused on the 
affect of school type on students' career maturity via ANOVA, Spearman's correlation and t-test. MANOVA is the main approach used in the research on the effect of career education module and gender on career maturity by Talib and other scholars [1]. In Katoch's study about career maturity of secondary school students, hypothesis testings, means, standard deviation and t-tests are mainly used to find the patterns.

However, these researches only focus on one or two factors, and the existing methodology may not be appropriate in the case where there are a large amount of factors. This research gap motivates our study, and we investigate the relationships between career maturity and a series of factors in the students' daily lives which may have potential effects on their career maturity. In this study, we collect data from senior high school students in Shenzhen, and analyze the 48 potential indicators. Several feature selection methods are employed, and we obtain 12 significant factors which may be related to career maturity.

\section{METHODS}

\subsection{Study Design}

In our study, 189 students from secondary schools in Shenzhen and Gansu were invited to participate in our survey. The survey included two parts. In the first parts, we evaluated their career maturity based on their responses to the survey designed by Liu [10]. In the second part, we collected students' answers to other questions that may influence career maturity used in previous researches, including estimations of students' career exploration, big five personality, family cohesion and adaptability etc.[14,15].For the questions including several choices, we normalized the score ranging from 0 (i.e., strongly disagree) to 5 (i.e., strongly agree). For those true-false items, their answers were turned into binary variables. In general, this part contains 40 quantity factors and 32 binary variables.

Following the previous studies $[12,16]$ that career maturity has linear relationships with several factors., we also used the linear regression to investigate the relationships between career maturity and other factors. However, since there were 72 variables and 189 observations, overfitting could not be avoided. In this study, we implemented two feature selection methods, forward stepwise regression and least absolute shrinkage and selection operator (LASSO), to identify the most significant factors. In order to compare the performance of the two methods, we used a 10-fold cross validation to evaluate their prediction accuracy and root mean square error (RMSE) was the evaluation criterion. We then used the better feature selection method to fit the linear model to investigate the relationship between career maturity and those factors. Though the statistical analysis of the results, we could find the significant factors as well as how they influenced the career maturity.

\subsection{Statistical Models}

\subsubsection{Forward Stepwise Regression}

Stepwise regression[17] with forward selection approach is a way to carry out linear regressions and prevent overfitting at the same time. It starts with an empty model, tests the improvements of the model after addition of each variable and adds the variable that its inclusion gives the most statistically significant improvement of the fit until there is no variables that can be added. 


\subsubsection{LASSO}

LASSO, or L1 norm penalized method [18], is one of the penalized regression methods, which is a kind of linear regression method that can prevent overfitting with measures to carry out variable selection. It carries out both variable selection and regularization in order to improve the accuracy of the model.

\section{RESUlts}

The RMSE of cross validation of linear regression, forward stepwise regression, and LASSO were $12.5,12.4$, and 11.7, respectively. Therefore, we applied LASSO to fit the whole data, and Table 1 shows the standardized regression coefficient $(\beta)$ and the lower bound $(0.025)$ and upper bound (0.975) of the $95 \%$ confidence interval of the coefficient for each predictor variables with non-zero coefficient in LASSO. Based on the p-value of the F test, 12 of the total 72 predictor variables were found to be significant to predict career maturity.

Table 1. Regression analysis for LASSO. Only the predictors with non-zero coefficients were listed

\begin{tabular}{|c|c|c|c|c|c|c|c|}
\hline Predictor & $\boldsymbol{\beta}$ & $\mathbf{0 . 0 2 5}$ & $\mathbf{0 . 9 7 5}$ & Predictor & $\boldsymbol{\beta}$ & $\mathbf{0 . 0 2 5}$ & $\mathbf{0 . 9 7 5}$ \\
\hline$\# 2$ & $-1.8738^{* *}$ & -3.552 & -0.196 & $\# 26$ & -1.0551 & -2.768 & 0.658 \\
\hline$\# 3$ & 1.0245 & -0.663 & 2.712 & $\# 27$ & 0.9840 & -1.006 & 2.974 \\
\hline$\# 4$ & -0.4258 & -1.933 & 1.081 & $\# 28$ & -0.6012 & -2.350 & 1.148 \\
\hline$\# 5$ & $-1.8816^{* *}$ & -3.757 & -0.006 & $\# 29$ & 1.1968 & -0.232 & 2.626 \\
\hline$\# 6$ & $-1.1212^{*}$ & -2.448 & 0.206 & $\# 30$ & 0.7832 & -0.331 & 1.898 \\
\hline$\# 7$ & -0.8366 & -2.541 & 0.868 & $\# 31$ & 1.1671 & -0.525 & 2.859 \\
\hline$\# 8$ & 0.0399 & -1.304 & 1.384 & $\# 32$ & 0.4635 & -0.872 & 1.799 \\
\hline$\# 9$ & -0.2375 & -1.578 & 1.103 & $\# 33$ & 0.3065 & -1.510 & 2.123 \\
\hline$\# 10$ & $-1.5136^{* *}$ & -2.679 & -0.348 & $\# 34$ & $1.6729^{* *}$ & 0.005 & 3.341 \\
\hline$\# 11$ & 0.8357 & -0.998 & 2.669 & $\# 36$ & 0.3898 & -0.953 & 1.732 \\
\hline$\# 12$ & 0.2722 & -1.349 & 1.894 & $\# 37$ & -0.0141 & -1.457 & 1.429 \\
\hline$\# 14$ & -0.5752 & -1.845 & 0.695 & $\# 38$ & $1.4364^{*}$ & -0.078 & 2.951 \\
\hline$\# 15$ & -0.4410 & -1.903 & 1.021 & $\# 39$ & 0.8561 & -0.951 & 2.663 \\
\hline$\# 16$ & 0.9304 & -0.279 & 2.139 & $\# 40$ & -1.2466 & -2.986 & 0.493 \\
\hline$\# 17$ & $-1.5808^{*}$ & -3.218 & 0.056 & $\# 41$ & $6.2343^{* * *}$ & 1.255 & 11.214 \\
\hline$\# 18$ & -1.1705 & -2.876 & 0.535 & $\# 43$ & $-13.7584^{* *}$ & -20.869 & -6.648 \\
\hline$\# 19$ & 0.8706 & -0.644 & 2.385 & $\# 45$ & $8.9205^{* *}$ & 3.496 & 14.345 \\
\hline$\# 20$ & -0.7723 & -3.349 & 1.804 & $\# 46$ & $7.0938^{* *}$ & 3.265 & 10.923 \\
\hline$\# 21$ & -0.9461 & -2.600 & 0.708 & $\# 48$ & -4.7518 & -11.033 & 1.529 \\
\hline$\# 22$ & -0.4540 & -1.929 & 1.021 & $\# 51$ & $-5.5741^{* *}$ & -9.479 & -1.670 \\
\hline$\# 23$ & 0.5553 & -0.853 & 1.964 & $\# 70$ & -3.3662 & -8.715 & 1.983 \\
\hline$\# 25$ & -1.0740 & -2.427 & 0.279 & $\# 72$ & 4.4005 & -1.065 & 9.866 \\
\hline
\end{tabular}

Note. The predictors were numbered from 1 to $72 . * * \mathrm{p}<.05,{ }^{*}<<.1$

\section{DISCUSSION}

In this section, we discussed the 12 important factors obtained by LASSO, and analyzed how they impacted the career maturity among students. 


\section{Factor 1: Educational level of fathers}

The educational level of students' fathers was very important to predict their career maturity. Without accepting a undergraduate or graduate level of education, fathers are unlikely to provide a comprehensive information of all the careers, especially for the elite jobs. So it is reasonable that the career maturity of a student who has a father with low educational level is relatively low.

\section{Factor 2: Frequency of mothers' companion}

Similar with Factor 1, the frequency of mothers' companion was also strongly related to students' career maturity. The more frequently a student stays with his/her mother, the more potentially he/she can acquire enough experienced guidance of the career.

\section{Factor 3: Academic performance at school}

The students who achieve higher grade point average (GPA) were investigated to have higher career maturity. In most cases, GPA is related with the ability to learn, the students with better learning ability is believed to have higher career maturity.

Factor 4: Level of involvement of social activities (i.e. extracurricular clubs, student union, religious groups etc.)

According to the results, the level of involvement of social activities is not positively related with career maturity. One possible explanation for this phenomenon can be that social activities is not necessarily helpful for gaining career maturity. Although leadership and group-cooperation skills can be trained during group activities, these might be not as significantly related to career maturity.

Factor 5: The level of agreement of the statement that GPA and the efforts are highly correlated

This factor is significant to predict the career maturity, but whether they are positively or negatively related is not confirmed as the confidence interval of the coefficient can be either positive or negative. This might be explained by the fact that students can misunderstand their efforts since it is too subjective.

Factor 6: The level of agreement of the statement that tough experience in lives and studying can gain the courage when facing difficulties

The result demonstrates that students who strongly agree that they have more courage when facing difficulties after experiencing hardships tend to have high career maturity. The students who strongly agree with the statement are more likely to gain experiences after going through some difficulties in the past. These characteristics of self learning and self reflection can help gain career maturity.

Factor 7: The level of agreement of the statement that I will insist my opinion even if others are opposed to it

Inferred from the results, the level of agreement of this statement is likely to have positive relationship with career maturity. Students who strongly agree with this statement are usually insisting on their decisions and opinions of future career. It is reasonable that those who easily 
change their opinion after other people's persuasion can appear fluid, and it is more difficult for them to really make a firm decision on career.

\section{Factor 8 - 11: Frequently used channels for obtaining information}

These 4 factors are binary variables, and generate from the same question about the students' frequently used channel for gathering information. The results of the four factors show that if students frequently search for information via publications (i.e. books, newspaper, magazines), portal sites (i.e. Sina, NetEase, Sohu, Tencent), or search engine (i.e. Baidu, Google), they tend to own higher career maturity. However, if students always gain knowledge through person-toperson communication, their career maturity seems to be low. The results show that objective channels are more reliable than subjective channels for students to acquire information and knowledge.

\section{Factor 12: Whether news is an important way to acquire information}

This factor is a binary variable, and the result demonstrates that students tend to have a lower career maturity when they have a strong need for daily news, including politics, economics, sports, and entertainments. A possible explanation for this result is that some fields of the news are irrelevant to foster career maturity.

\section{Conclusion}

In this study, we developed a reasonable method to evaluate the relationship of career maturity with a branch of potential factors. The results show that LASSO is a reliable model to select essential factors. We also found that several factors which were not studied in previous studies were important to predict career maturity. However, this model has some limitations: first, the model only considered the linear relationship and non-linear relationship could also exist between career maturity and certain factors; second, the design of questionnaire might have deficiency and more factors should be included; third, the sample size is too small and more students in all the grades from different regions should participate. Those are all further directions in this research field.

\section{REFERENCES}

[1] Jasmi, Talib, A. , Amla, Salleh, Salleh, \& Amat, et al. (2015). Effect of career education module on career development of community college students. International Journal for Educational \& Vocational Guidance.

[2] Ballout, H. I. (2009). Career commitment and career success: Moderating role of self-efficacy. Career Development International, 14, 655-670.

[3] Roaten, G. (2004). The effects of a career development intervention on the career decision making skills of high school students. Unpublished Doctoral Dissertation, Texas A\&M University, College Station, TX.

[4] Rohany, N. (2008). Career counseling, shift from konvensionalisme, Prime Professor Lecture Series UKM. Bangi: Penerbit Universiti Kebangsaan Malaysia.

[5] Guide on Life Planning Education and Career Guidance for Secondary Schools, 1st edition, Career Guidance Section, School Development Division, Education Bureau(May 2014)

[6] Does the College Major You Choose Affect Your Career Potential? https://www.moneycrashers.com/college-major-career-potential/. Accessed August 9, 2020.

[7] Donald E. Super. (2005). Dimensions and measurements of vocational maturity. Teachers College Record.

[8] Crites, J. O. . (1975). A comprehensive model of career development in early adulthood. Journal of Vocational Behavior, 9(1), 105-118. 
[9] Patton, W. , \& Creed, P. A. . (2011). Developmental issues in career maturity and career decision status. Career Development Quarterly, 49.

[10] Linhui, L. , \& Jiajia, L. . (2011). Current situation and relationship study on career anchor and career maturity of college students. Science of Social Psychology.

[11] In-Jo, P. . (2015). The role of affect spin in the relationships between proactive personality, career indecision, and career maturity. Frontiers in Psychology.

[12] Allen, Dara Ware. (2008). Career maturity and college persistence: a longitudinal study of first-year students. Dissertations \& Theses - Gradworks.

[13] Abdul Rahim, Nor Syazila and Mohd Noah, Sidek and Wan Jaafar, Wan Marzuki (2018) Career maturity among students from three different types of school. International Journal of Education, Psychology and Counseling, 3 (7). pp. 8-17. ISSN 0128-164X

[14] Nadya A. Fouad, \& Timothy J. Keeley. (2011). The relationship between attitudinal and behavioral aspects of career maturity. The Career Development Quarterly.

[15] Mcauliffe, G. J. . (1992). Assessing and changing career decision-making self-efficacy expectations. Journal of Career Development,19(1), 25-36.

[16] Houle, J. L. W. , \& Kluck, A. S. . (2015). An examination of the relationship between athletic identity and career maturity in student-athletes. Journal of Clinical Sport Psychology, 1538(1), 119-128.

[17] Efroymson,M. A. (1960) "Multiple regression analysis," Mathematical Methods for Digital Computers, Ralston A. and Wilf,H. S., (eds.), Wiley, New York.

[18] Bowles, M. . (2015). Penalized Linear Regression. Machine Learning in Python®. John Wiley \& Sons, Ltd.

\section{AUTHORS}

Shuxing Zhang is a high school student in Grade 12, and her research interests are data mining and education. While having a background in Python programming and being the 3rd author in two published Python algorithm books, she is also concerned about the problem of enhancing Chinese high school students' career maturity.

Qinneng Xu got his Phd degree in the School of Data Science, City University of Hong Kong, Hong Kong SAR, China. His research interests are data mining and bioinformatics, and he has published several papers in the fields of infectious diseases and public health.
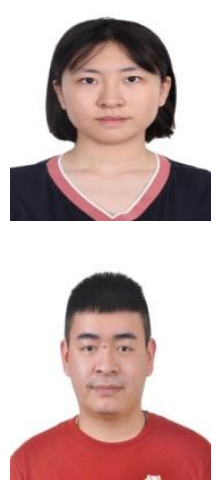

(C) 2020 By AIRCC Publishing Corporation. This article is published under the Creative Commons Attribution (CC BY) license. 